\title{
Discussion on "Protection of Cables from Arcs Due to Failure of Adjacent Cables."
}

RALPH D. Mershon: In addition to the protection of cables in manholes, there is also the question of the protection of cables in power-stations. It is not always easy to install cables in such a way that they will be protected from each other, especially if the power-house has not been laid out with reference to them. The question of protecting cables by means of asbestos and similar wrappings has for its chief objection that there is no chance to get rid of the heat in the cable. For that reason, and for the greater one of reliability, the speaker very much prefers either tile or brick protection to asbestos.

Mr. Carlton speaks of using a voltmeter for determining the current being carried by the cable sheath. Will Mr. Carlton please explain a little more fully the method of using the voltmeter, and also the method he prefers for permanent grounding of metal sheaths?

W. F. Wells: Mr. Carlton refers to two independent lines of subway as being an insurance against trouble on a high-pressure cabie system. In New York this practice has been carried a little further, and four separate and independent trunk subways have been installed, leading from the generating station along four different routes. From these trunk subways run branches arranged so as to give each substation two or more feeders, following entirely different subway routes. In case of a manhole caving in, or general trouble on any subway line, not more than one quarter of the high-pressure cable system can be affected.

Regarding the injury to high-pressure cables by the burning out of low-pressure cables; this has occurred, but burn-outs have also originated in the high-pressure cables. Some of these troubles were due to defective joints and some to short bends in the cable where it leaves the duct. In order to obviate this latter cause, the cable is now run straight out of the duct 12 in. before bending it over to the side of the manhole, thus preventing the edge of the duct from cutting into the sheath of the cable.

For the past two or three years the high-pressure cables in manholes have been wrapped with asbestos bound on by galvan1zed-steel tape, as described by $\mathrm{Mr}$. Carlton, and the results have been very satisfactory. No trouble has been experienced from the heating of the cables where covered with this asbestos wrapping. In the stations, clay ducts or iron pipes are used wherever possible to protect the lead-covered cables, and, when there is sufficient space, braided cables are carried on insulators through runways of brick 12 -in. square.

H. C. Wirt: Will Mr. Carlton state whether he considers an underground line more reliable than overhead line as regards interruption of service?

Ralph D. Mershon: Mr. Carlton speaks of the extra ex- 
pense of separating ducts. It seems that in some cases separation may not in the end be an extra expense. The capacity of the subway is not necessarily proportionate to the number of ducts in it. Allow a certain limiting value to the temperature of the cable, then the ducts near the center of the conduit will not be as effective as those outside, no matter how they are arranged; if they are separated, it might be cheaper in the end because of the greater capacity the two subways would have over the single. So far as the speaker knows there are no accurate data in regard to this matter. The speaker has done a little work himself in special cases, and some work was done at Niagara some time ago. Perhaps Mr. Carlton and Mr. Wells have some information on this subject.

W. G. CARLTON: In regard to the capacity of the cable being lessened in a larger conduit line; the speaker has no accurate information on that subject. Where cables are run at extremely heavy loads the gas generated inside of the cable will puncture the lead sheath, and this is one of the limiting features. The permissible watt consumption per linear foot of cable depends on the number of cables in one conduit line. With a single cable 20 watts per foot would probably be safe; with a larger number of cables, three or four might be the limit.

It is a good plan to treat the cables in the power-house-if they are lead-covered ones-practically the same as you would for underground construction. A conduit line can either be built, or when the cables are in place they can be covered with split clay tile. The ends of the cables need special care. Threeconductor cables must have some sort of terminal bell which allows spreading out the conductors for connection to the singleconductor cable, this bell to be filled with an insulating compound.

In regard to detecting possible stray currents on the lead sheaths of cables; a Bristol recording meter with a five-volt scale has been used; this is fairly satisfactory. A meter with the zero line in the middle of the chart and giving readings each side of this line would be much better. The voltmeter is connected between the lead sheath of the cable and a good ground. In our stations we connect with the ground plate; we have a ground bus-bar in our stations connected to several ground plates. In a manhole it would be connected to a waterpipe or sometimes to the cast-iron frame of the manhole or to a rod driven in the ground. The grounding of the cable sheaths is done ordinarily in the power-house, on the brass bell on the end of the cable.

Answering Mr. Wirt's question in regard to overhead and underground lines; in the case of one company operating possibly 75 miles of 9000 -volt lines, 65 of which is underground, possibly $90 \%$ of the trouble on the lines is on the 10 miles of overhead line. This has been caused generally by boys throwing wires over the line, or by kite-strings. 
H. B. Alverson: When the asbestos covering a cable is saturated with silicate of soda, the wrapping will harden and become nearly as good a conductor of heat as the lead jacket; this overcomes the objection that asbestos covering confines the heat within the cable.

W. G. Carlton: How does that stand in a wet manhole?

H. B. Alverson: We have had no experience of that sort.

E. M. LAKE (by letter): In visiting some of the larger Eastern stations, about three years ago, it was observed that very little attention had been given at that time to the protection of outgoing cables. The bus-bars and immediate connections were protected by a most elaborate scheme of barriers built up of brick and concrete and of soapstone. The outgoing feeder lines, however, and in one or two places the main leads from the generators, were laid side by side upon cast-iron racks or upon thin sheet-steel shelves.

When this question came up in connection with the design

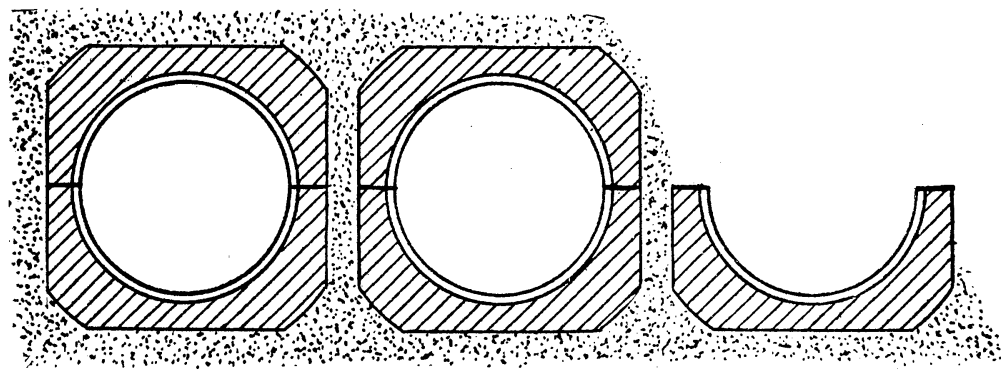

$$
\text { FIG. }
$$

of certain Chicago sub-stations several methods were considered for protecting and isolating the whole cable equipment so as to reduce to a minimum the liability that a burn-out would spread to adjacent cables. The plan of using thin slabs of slate or vitrified clay was not found feasible because of the difficulty of applying in places where the structural work and cables were already in place. Then, too, this plan did not afford a simple and ready method of completely enciosing the cables where there were several in one run. Steel shelving and partitions when used alone were open to the same objections, besides being still further objectionable on account of the very small resisting power when subjected to the intense heat of an electrical burn-out. The proposition then narrowed down to some form of vitrified clay conduit because of the convenience of form, good mechanical strength, and high arc-resisting powers. Since the application must very often be made to - cables in place, a split or divided form was necessary. There were found two forms of split conduit. One was divided in a straight line upon the diameter of the bore (Fig. 1). The other 
was divided at an angle to the diameter, the two parts not being symmetrical (Fig. 2). These conduits were each applicable to certain conditions and locations, but a form was desired that would adapt itself readily to any and all places where protection of this kind was required. The style designed for this purpose was divided on lines parallel to the diameter of the bore but offset about an inch with reference to the diam-

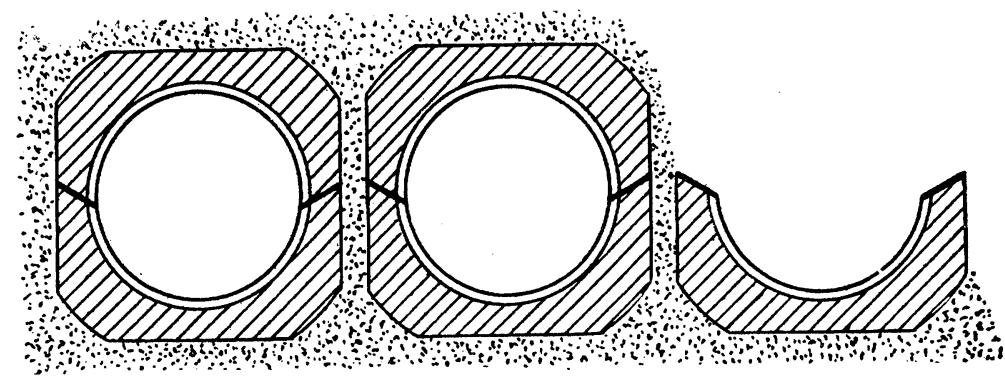

F,G. 2 .

eter (Fig. 3). This gave two symmetrical sections which were interchangeable and possessed several distinct advantages over the existing forms.

It will be observed that in this form of conduit the joints in two adjacent ducts are not directly opposite. This of course insures a much more effective barrier between the cables enclosed by the conduit. For horizontal runs in walls the form

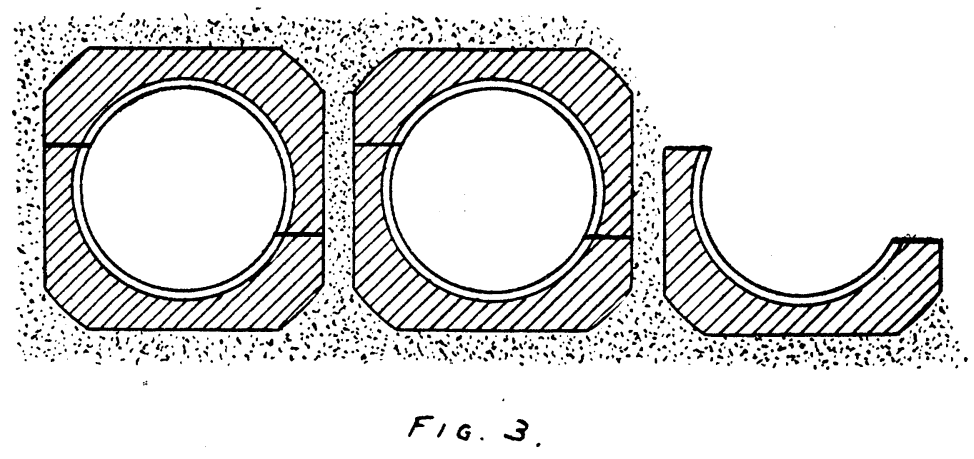

of the half-section is such that when laid it forms a convenient bed for the cable. Then when the cable is in place it does not form an obstruction to the laying of the remaining half of the conduit. Elbows on a safe radius for large cables and in an arc of 45 degrees were provided. Short straight lengths of $4 \frac{1}{2}$ in. and 9 in. were also ordered. With these forms and the standard 18-in. lengths it was comparatively easy to follow 
the curves of any run of cables in a station or manhole, provided the cables had not been laid on less than a 12 -in. radius.

A. M. Hunt (by letter): A covering for leaded cables where exposed in manholes can be made as follows: mix a stiff mortar using calcined magnesite (finely ground) and a saturated solution of magnesium chlorid; this combination hardens to stone in a few hours, and is heat-resistant and water-proof. Coat the lead of cable with oil, and wind it spirally with strips of canvas, putting the mortar on the inside of strip as the winding progresses. Any thickness of coating may be built up in this way. An outside finish of the mortar should be used. If the lead is not oiled, the mortar will adhere to it strongly, and be difficult to remove. The materials can be bought at prices which do not make the cost of such work heavy, and the covering is solid and effective.

As a protection against electrolytic action on the lead sheath of cables in an extensive network, the writer has tried operating a direct-current machine of low pressure with the negative terminal solidly connected to the lead sheathing and the positive strongly bonded to rails. The sphere of influence of this machine was much more extensive than might be imagined, and the application is worthy of consideration in cases where electrolytic action is severe. In the case noted the energy consumed was quite small.

J. W. F. Blizard (by letter): The writer suggests wrapping the cable in manholes with tape or thin asbestos, and then spreading a layer of about one-eighth inch of litharge on the cable. This will harden quickly and form a perfect protection from arcs, and may with ease be extended into the ducts for an inch or two. Ground mica and varnish would probably prove equally satisfactory, and cost considerably less. The asbestos or tape covering would prevent the compound used from adhering to the cable sheath, thus making the cable accessible in case of trouble, by simply breaking the protecting shell.

In addition to the dangers arising from the unconfined arc mentioned by Mr. Carlton, there is the often very serious one of gas explosions. No good ventilating system for underground conduits having yet been devised, this danger is an ever present one, and its importance should not be underrated. 